\title{
Escritos breves para circular \\ Relações, notícias e avisos \\ durante a Alta Idade Moderna (sécs. XV-XVII)
}

\section{Writing to Circulate}

Reports, News, and Notification

in the Early Modern Period $\left(15^{\text {th }}-17^{\text {th }}\right.$ centuries $)$

Ana Paula MEGIANI ${ }^{1}$ https://orcid.org/0000-0002-3638-8567

${ }^{1}$ Departamento de História

Universidade de São Paulo

Avenida Professor Lineu Prestes, 338, Butantã, São Paulo, SP, 05.508-900, Brasil megiani@usp.br

Resumo A circulação de notícias surgiu na Europa em meados do século XV como forma de satisfazer a curiosidade e interesse de pessoas sobre acontecimentos que começavam a se tornar mais notórios. Relatos de viagens, batalhas, milagres, descobertas, fenômenos naturais e sobrenaturais passaram da oralidade para os manuscritos e, com a invenção da prensa de tipos móveis, também impressos, acrescentados de imagens em gravuras. África, Ásia e América são incorporados. Ao longo dos séculos XVI e XVII a circulação de notícias adquire um movimento mais intenso, levando ao aparecimento dos primeiros periódicos denominados mercúrios e gazettes, que entretanto convivem com as notícias manuscritas. Em todas as partes, colecionadores de relações,

Recebido: 19 nov.2018 | Revisto pelo autor: 11 mar. 2019 | Aprovado: 06 abr. 2019 http://dx.doi.org/10.1590/0104-87752019000200007

Varia Historia, Belo Horizonte, vol. 35, n. 68, p. 535-563, mai/ago 2019 
avisos, e notícias criam acervos de miscelâneas que merecem ser vasculhados. A compreensão desse processo permite refletir acerca das novas modalidades de escrita, mais breves, mais ágeis e efêmeras que passaram a informar à distância, acompanhando o movimento das viagens e a circulação de pessoas pelo mundo. As novas técnicas de impressão de textos e imagens e a agilidade da distribuição também fazem parte desse movimento que ganha, além disso novas dimensões - política e econômica - durante a Alta Idade Moderna.

Palavras-Chave cultura escrita, circulação de notícias, alta idade moderna

Abstract The circulation of news emerged in Europe in the mid-1400s as a way of satisfying people's curiosity and interest in events that had begun to become well known. Reports about travel, battles, miracles, discoveries, and natural and supernatural phenomena transitioned from the oral medium to manuscripts, while after the invention of the movable type press printed supports with added engravings became possible. Africa, Asia and Americas were incorporated. During the sixteenth and seventeenth centuries the circulation of news became more intense, leading to the appearance of the first periodical publications called Mercuries and Gazettes. Nonetheless, manuscript news kept on circulating. Everywhere collectors of reports, notifications, and news created collections of miscellanea that deserve to be examined. Understanding this process allows reflection on new modalities of writing: briefer, more agile, and ephemeral, which were capable of providing information from afar, following the dynamics of travel and the circulation of people around the world. The new techniques for printing texts and images and the agility for distributing them are part of this movement, which, during Early Modern times, acquired further political and economic dimensions.

KEYWORDS written culture, news circulation, early modern 
Seguir a pista da difusão das grandes notícias é também uma maneira de medir velocidades excepcionais. As notícias têm asas. (...) Em qualquer caso, toda medida deve ser vista com precaução, desde o momento que está confinada em um só número. E não nos esqueçamos do que realmente estamos medindo. A velocidade das notícias (...) não é mais que um capítulo da luta contra o espaço. (Braudel, 1997, p.479)

No dia 14 de maio de 1610, o rei da França, Henrique IV (1553-1610), foi esfaqueado e morto em uma rua de Paris por um homem até então desconhecido, François Ravaillac, que alegou motivos religiosos ao ser interrogado pelos investigadores do crime. Trata-se de um acontecimento estarrecedor para a época, e mesmo hoje, às vésperas do início da segunda década do século XXI, uma notícia como esta - o assassinato de um chefe de estado, seja ele rei, presidente, ou primeiro ministro de uma das mais importantes nações do planeta - ocuparia integralmente os meios de comunicação (rádios, TVs, redes sociais) como um fato extraordinário, no sentido mais primário que esta palavra possa ter, isto é, fora do comum. Entretanto, para despertar interesse, não é essencialmente necessário que o assunto tenha, ou tivesse, forte impacto político, bastava ser extraordinário. $\mathrm{O}$ regicídio francês foi um assunto, dada sua excepcionalidade e relevância, que despertou interesse e curiosidade em todas as partes da Europa, e fora dela. Os correios de avisos diplomáticos foram imediatamente acionados, e em poucos dias os embaixadores franceses nas principais cortes europeias estavam informados do ocorrido. Mas a notícia não chegaria apenas aos funcionários e representantes em ambientes políticos. Em geral, as pessoas que viviam em cidades como Madrid, Lisboa, Londres, Amsterdã, Antuérpia, Roma, Bolonha queriam saber o que se passava em Paris e quais os detalhes do episódio que, afinal, havia sido prenunciado por Nostradamus em 1589, quando esteve a serviço da corte de Navarra (Crouzet, 2011). Quem era o assassino? Como foi cometido o crime? 
Que motivos ele teria para cometê-lo? As perguntas davam proporção ainda maior aos rumores. Segundo Augustin Redondo, sobre esse episódio foram impressos um sem número de relatos avulsos em francês, inglês e espanhol, e além deles, tantos outros manuscritos, sobretudo copiados dos impressos (Redondo, 2015). E é a partir desse acontecimento extraordinário e surpreendente que iniciaremos nossa reflexão sobre escritos breves para circular e a importância dos impressos avulsos durante a Alta Idade Moderna.

O interesse das pessoas por acontecimentos que não sejam ordinários, rotineiros, cotidianos, existe desde o início dos tempos. A curiosidade e o medo podem estar relacionados a esse interesse, já que a novidade pode ser ameaçadora da paz e da tranquilidade, demandando precaução e preparo emocional. Saber o que se passa fora de casa é um aspecto da vida que toca diretamente o que poderíamos definir como, sem grande pretensão, instinto de sobrevivência com vistas à organização da defesa, tanto pessoal quanto coletiva. O tema parece um pouco geral se tomado assim sem uma definição teórica, mas dado que o interesse e a curiosidade fazem parte das estruturas mentais que dão sentido à vida humana, desde os tempos mais remotos existem também os meios e mecanismos para o envio de notícias, avisos, informes, comunicados e informações, em todas as organizações sociais. O que hoje conhecemos como correio (mail, post, courier) é uma das instituições mais importantes na formação de redes de comunicação e circulação de notícias, desde a Antiguidade (ocidental e oriental), e esteve presente em todas as formações políticas conhecidas, bem como nas relações de informalidade. Notícias verdadeiras ou falsas, escritas ou orais, enviadas por portadores humanos ou animais, e mesmo por meio de objetos ou invólucros, e atualmente digitais, possuem um aspecto comum: a necessidade de comunicar uma informação relevante.

Neste artigo nos dedicaremos a pensar acerca da produção e circulação de notícias durante a Alta Idade Moderna, isto é, entre os séculos XV e XVII, e principalmente após a invenção da imprensa na Europa, quando a notícia ganha novos meios, suportes e mecanismos de divulgação, passando a compor um sistema que se tornará dominante nos 
Estados monárquicos e seus domínios. Vale observar que, decidimos neste artigo privilegiar uma reflexão acerca dos meios de comunicação e informação de notícias avulsas, assim como dos elementos que constituíram esse processo, especificamente a circulação de notícias. Nosso interesse é tentar apresentar, de maneira ampla e geral, as principais características dos objetos impressos e manuscritos que circularam como portadores de notícias, e como eram, em certa medida, "colecionados" por alguns indivíduos, motivados pelo desejo de organização e sistematização da memória de seu tempo. Escrita, leitura e cópia de notícias constituíram ricas coleções de volumes impressos e manuscritos de uso de letrados nos reinos e nas regiões de conquistas, configurando um patrimônio que deve ser considerado em seus vários aspectos, para além do conteúdo que carregam. Conhecer, descrever e analisar esses conjuntos de escritos, além de gravuras e mapas que circularam e foram objetos de coleções, reunidos por uma pessoa, ou por uma instituição, nos permite aprofundar a reflexão acerca de modos de fixar, circular e colecionar saberes à distância.

Seguramente, um historiador do século XX ou XXI que queira entender as motivações político-religiosas e os problemas que envolveram o assassinato de Henrique IV não poderá se basear apenas nos folhetos impressos que circularam intensamente relatando esse acontecimento. Mas, se esse mesmo historiador tiver interesse em saber como essa notícia foi recebida pelas pessoas em geral, em diferentes partes da Europa e fora dela, certamente ele deverá dedicar-se às folhas soltas, panfletos impressos e suas cópias manuscritas surgidos nos anos que se seguiram. Consideramos que impressos e manuscritos noticiosos avulsos tiveram papel fundamental na construção de relatos e narrativas acerca de acontecimentos extraordinários na cultura ocidental, principalmente a partir do século XV, o que tem levado pesquisadores a dedicarem-se, cada vez mais, a entender como era o processo de produção, circulação e colecionismo desses textos efêmeros que nem sempre foram tratados como fontes relevantes para análise do passado. Os estudos sobre panfletos avulsos e a circulação de rumores e notícias nas cortes, reinos e cidades do Antigo Regime vêm cada vez mais sendo objeto de interesse por 
parte da historiografia ocidental, sobretudo a partir de obras pioneiras de Robert Darnton e Roger Chartier (Darnton, 1990; Chartier, 1998; 2004). O volume bibliográfico produzido, entretanto, já ultrapassa as centenas, e por isso não indicaremos aqui.

Mesmo antes do surgimento da tipografia nas principais cortes europeias havia grande interesse por notícias e informações sobre os mais diversos assuntos. Mas não só nas cortes, pois em cidades e vilas também chegavam as notícias, seja por via manuscrita ou oral, já que relatos costumavam ser lidos, ouvidos e recontados em praças e feiras, pois, como afirma Ana Buescu, "num tempo do livro raro, como era o tempo da civilização medieval, o homem era, em termos da transmissão da cultura e do saber, essencialmente 'auditivo'. (...) Em contraste, o 'homem tipográfico' será sobretudo 'visual'” (Buescu, 2000, p.31). Nesse sentido, a notícia que circulava predominantemente por meio oral, e que por isso mesmo tinha um caráter atemporal, começa aos poucos a ganhar cada vez mais sentido de precisão e fixação com datas, dias e anos definidos. No mesmo processo, a partir do século XV, à medida que o mundo passa a ser conhecido pelos europeus por meio das viagens marítimas, a metrificação e contagem do tempo torna-se um elemento definidor da sociedade ocidental.

No século XVII, o significado do termo notícia, segundo o Tesoro de la lengua castellana o española, decorre do latim notitia; cognitio, é dado como "el conocimento de alguna cosa", simplesmente conhecer. ${ }^{1}$ Já no século XVIII, para Raphael Bluteau existem notícias certas como a ciência, e notícias duvidosas ou escuras, como a opinião. ${ }^{2} \mathrm{O}$ termo Suceso por sua vez, comumente encontrado no título das folhas de notícias e acontecimentos, não aparece no Tesoro de la lengua castellana,

1 COVARRUBIAS HOROZCO, Sebatián de. Tesoro de la lengua castellana o española. Madrid: Luis Sanchez impresor del Rey, 1611. p.565. https://archive.org/details/A253315/page/n53 Acesso em 28 mar. 2019.

2 BLUTEAU, Raphael. Vocabulario portuguez \& latino: aulico, anatomico, architectonico. vol. V. Coimbra: Collegio das Artes da Companhia de Jesu, 1712 - 1728 http://dicionarios.bbm.usp. br/pt-br/dicionario/edicao/1 Acesso em 15 nov. 2018. 
enquanto em Bluteau significa "cousa que tem sucedido." ${ }^{3}$ Portanto, podemos afirmar que a relação entre notícia e sucesso foi estabelecida durante esse processo, pois informar os fatos ocorridos, sejam eles quais forem, é também uma forma de conhecimento.

O processo de ampliação das conexões entre todas as partes do globo a partir do século XV, acelerou esse interesse de saber e conhecer, deflagrando uma forte onda de produção de informações que ultrapassaria o âmbito sigiloso político e militar, ganhando espaço em ambientes externos às cortes. Diferentemente dos textos de História, Teologia, Filosofia e Direito, definidos por estruturas preceptivas da arte da Retórica, ou das crônicas e narrativas literárias, ou ainda qualquer outro tipo de saber chancelado pelas instituições formais e produzido em ambientes clericais - monásticos ou universitários - laicos, eruditos e acadêmicos (estes a partir do século XVII), os textos noticiosos não eram determinados por preceitos ou modelos de autoridade, e podiam ser referentes a assuntos muito variados, motivados principalmente pela curiosidade. Assim, qualquer pessoa que tivesse presenciado um acontecimento, ou escutado um relato sobre ele, estava apta a redigir uma notícia, o que determina uma grande diversidade de formatos sobre um mesmo acontecimento, inclusive com episódios e desfechos diferentes. Por outro lado, amplia-se a intensificação da circulação de informações, saberes, relações de notícias impressas e manuscritas em todas as partes conectadas pelas viagens ultramarinas, circulação esta necessária nos modos de governar à distância entre instituições metropolitanas e coloniais, ou entre representantes das diversas ordens religiosas distribuídas nos recônditos territórios ocupados pela religião católica em comunicação com seus principais (Pieper, 2005).

Nesse sentido, reforçamos que os documentos noticiosos escritos nos séculos XVI e XVII, sejam eles impressos ou manuscritos, não podem ser tratados como embriões do periodismo oitocentista ou contemporâneo, tal como costumam afirmar, anacronicamente, os estudiosos

3 BLUTEAU, Raphael. Vocabulario portuguez \& latino: aulico, anatomico, architectonico, op. cit., p.711. 
desse campo. Diferentemente dessas opiniões, compreendemos que eles pertencem a um momento específico da cultura ocidental, cujos procedimentos de registro, seleção e organização dos assuntos em miscelâneas e coleções eram realizados segundo códigos próprios. Assim, nos parece fundamental levar em conta o caráter hierárquico da sociedade europeia que se volta para o novo mundo, na qual um indivíduo apenas por ser letrado não tinha garantido seu espaço de atuação junto às diversas esferas de poder e domínio existentes. Outros elementos de tradição e negociação eram necessários para que o portador de conhecimento de letras pudesse ocupar cargos, receber honras, mercês e privilégios régios, como a limpeza de sangue, entre outros (Bouza, 2006). Apesar disso, uma monarquia moderna não podia existir sem uma corte de letrados, além de diversos conjuntos de obras impressas e copiadas, assim como as principais casas nobres dos reinos europeus não podiam prescindir do status de possuir livrarias, coleções de pinturas, gravuras e mapas, sustentando para isso clientelas ligadas ao conhecimento da natureza, à produção artística e ao registro da história (cf. Rueda Ramírez, 2012).

Relações de Sucessos, de Avisos ou de Arbítrios; inicialmente eram essas as denominações mais comuns que encontramos em Portugal, Espanha, Itália, França e Inglaterra para os textos noticiosos. Embora haja significativa diferença entre eles, não é possível diferenciá-los ou classificá-los por categoria, já que não havia uma tipologia definida, pois não se trata de um gênero de escrita preceituado nas artes da retórica, e sim de textos que, em geral, ocupavam pouco espaço em papel e podiam ser anexados a cartas e dentro de livros, ou nos mesmos volumes. Durante os séculos XV e XVI não há sequer registro da existência de periodicidade das folhas noticiosas, mesmo as impressas. Sua natureza efêmera foi, durante muito tempo, a causa de terem recebido pouca atenção dos historiadores que as consideravam irrelevantes como fontes.

Não temos como precisar quando as Relações de Sucessos se diferenciaram das Relações de Avisos. Já os Arbítrios adquirem especificidade ao longo do século XVI, à medida que passam demonstrar certo teor opinativo e a receber reconhecimento da nobreza e dos monarcas, como proteção e patrocínio devido à necessidade de ampliação do escopo da 
governança. As Relações de Avisos caracterizam-se por serem relatos mais sintéticos, de menor intensidade narrativa, organizadas a partir de locais de origem como França, Flandres, Inglaterra, Espanha, Índias Orientais, Milão, Nápoles, Roma, etc; e serviam para informar em um só texto sobre os acontecimentos ocorridos em diversas partes. Segundo Carmem Espejo, é muito provável que as relações de avisos fossem alimentadas pelas Relações de Sucessos, o que limita a originalidade e o ineditismo do conteúdo delas (Espejo, 2008). Nesse sentido, os autores dos Avisos são, geralmente, pessoas bem informadas e bem relacionadas em redes de correspondentes, com tentáculos lançados em várias partes do continente e do globo. Um exemplo desse tipo de rede é aquela com a qual trabalhamos anteriormente, formada pelo clérigo português Manuel Severim de Faria, autor de Avisos enviados para Diogo do Couto, cronista das Índias (Megiani, 2009). Já uma Relação de Sucessos costumava referir-se a um só acontecimento ou tema, um evento da corte - casamentos, nascimentos, entradas régias -, ou batalha, fenômeno natural - terremoto, passagem de cometa, furacão -, mas não é raro encontrarmos vários assuntos reunidos em uma só Relação. Por isso, a diferenciação entre Relação de Sucessos e Relação de Avisos não pode ser levada com rigor. A autoria também costuma ser indicada, quando impressa, e frequentemente o nome do impressor, cidade e mesmo o patrocinador. Há inúmeras coleções desse tipo de impressos por todas as bibliotecas e arquivos na Europa, nos EUA e América Latina. Em pleno século XVIII o erudito Diogo Barbosa Machado dedicava-se, ainda, a colecionar esse tipo de publicação (Monteiro; Caldeira, 2007).

A inconstância da narrativa e irregularidades no modo de descrição são algumas das características que tornam esse tipo de objeto ainda mais interessante. Os conteúdos poderiam girar em torno de assuntos externos, locais, sociais, acontecimentos naturais ou sobrenaturais, e de eventos festivos, políticos, religiosos, tais como batalhas, autos de fé, milagres, catástrofes naturais, desgraças pessoais e ainda relatos de viagens imaginárias ou reais. Mas, como estamos tratando de um tempo em que as classificações eram diferentes das nossas, e seus objetivos eram claramente estabelecidos, sua compreensão deve passar pelas lógicas de 
ordenamento hierárquico características da cultura do Antigo Regime. Uma batalha distante e um batizado na corte poderiam ser assuntos integrados na mesma relação, bem como um casamento real e uma rebelião local, desde que se tratassem de fatos ligados a um mesmo nível hierárquico de poder. Quando começamos a separar as notícias em sociais, políticas, culturais, nacionais e internacionais, criamos a sensação de que essas dimensões podem não estar relacionadas entre si, cabendo aos indivíduos mais críticos fazerem as pontes e ligações. No Antigo Regime não havia espaço para leituras pessoais ou individuais, já que as narrativas davam conta, elas mesmas, de integrar milagres de santos e batalhas vitoriosas, profecias e catástrofes naturais associadas a quedas de governantes considerados usurpadores. A natureza, a política, a guerra e o sobrenatural eram partes de um todo ordenado por Deus, segundo seus desígnios, e vivido pelos homens (Koselleck, 2006).

No tocante à forma, as Relações de Sucessos apresentavam também extensão variável, embora as mais comuns fossem a relações de dois fólios frente e verso, podendo ocorrer também as de uma folha, um pliego, ou um pequeno livro de cordel, ou ainda um livro mais volumoso, quando se tratava de um evento com vários episódios. Parte significativa dos autores era formada por desconhecidos, mas a declaração de autoria também pode ser frequente, ou seja, não existe um padrão claro de autoria. Os especialistas em Relações de Sucessos espanholas demonstraram em suas pesquisas que, geralmente, um editor encarregava-se de recolher um, ou vários, relatos de acontecimentos para publicá-los, tendo alguns deles se tornado conhecidos por possuírem uma rede de informantes e realizarem suas atividades de recopilação e edição na primeira metade do XVII, dentre eles Juan Serrano de Vargas e Juan Gómez de Blas, ambos estudados por Carmen Espejo (Espejo, 2008).

Identificamos também que, no contexto da lógica das dedicatórias a membros destacados da corte e busca por reconhecimento por serviços prestados, algumas Relações de Sucessos e Avisos, originalmente elaboradas como notícias, vieram a se tornar obras mais elaboradas para publicação, como é o caso conhecido da Jornada dos Vassalos, escrita por D. Jeronimo de Ataíde. Inicialmente pensada para ser uma Relação 
de Sucessos, assim como outras que foram escritas sobre os mesmos acontecimentos - a tomada da cidade de Salvador da Bahia pela esquadra holandesa e sua expulsão pelas armadas católicas de D. Fabrique de Toledo em 1624/25 - a narrativa impressa torna-se um texto referência para a exaltação da vitória dos católicos contra os protestantes, os episódios da batalha e seus mais destacados combatentes. Segundo S. Schwartz, "publicaram-se grandes quantidades de crônicas e relatos dos acontecimentos, muitos dos quais escritos por participantes, observadores e historiadores. Ninguém que tenha prestado serviço nas tropas vitoriosas deixou, desde então, de mencionar os seus serviços para obter recompensas ou favores" (Schwartz, 2003, p.144-145). O caso do texto de Ataíde é muito interessante, porque de Relação de Sucesso manuscrita passa a crônica, ganhando status e reconhecimento e memória política (Magalhães, 2016).

Segundo Mariana Sales, também na Coleção Mazarin - Manuscritos Ibéricos da BNF encontra-se um volume dedicado a esses relatos da expulsão dos holandeses do Brasil. "Embora constitua uma antologia de manuscritos, nele também se encontra um exemplar impresso do texto de Francisco de Avendaño y Vilela, Relacion del viaje y sucesso de la armada que por mandado de su Magestad partio al Brasil, a echar de alli los enemigos que lo ocupavam (apud Sales, s/d). ${ }^{4}$ Narrativas sobre as esquadras e os contingentes de soldados de diferentes nacionalidades, as batalhas, os episódios naturais concomitantes aos acontecimentos bélicos invadiram as prensas e oficinas de copistas, geralmente escrito por soldados presentes nas batalhas. A relação de textos impressos sobre o episódio de expulsão dos holandeses da Bahia, em castelhano e português, escritos em diversos gêneros, entre eles a peça de Lope de Vega. Além dos impressos, menciona a existência de manuscritos localizados em arquivos espanhóis e mesmo napolitanos, compostos por soldados que participaram nas tropas de combate. Para Schwartz, os relatos da

4 Francisco de Avendaño y Vilela. Relacion del viaje y sucesso de la armada que por mandado de su Magestad partio al Brasil, a echar de alli los enemigos que lo ocupavam. Sevilla: Francisco Lyra, 1625. 
jornada de 1625 constituem um momento de virada nas relações entre os vassalos e as coroas unidas sob os Habsburgo, e a partir da análise desses textos apresenta, "por um lado, a luta entre certos grupos sociais na sociedade ibérica e, por outro, os pontos de relação desses grupos com o Estado" (Schwartz, 2003, p.144-145).

Desse modo, o crescente interesse das pessoas pelas informação e notícias veio somar-se a um contexto de hibridismo das formas e práticas correntes de escrita, e podemos arriscar a hipótese de que o fenômeno foi incentivado pelo adensamento populacional urbano europeu ao longo dos séculos XVI e XVII, com o crescimento das praças mercantis como Amsterdã e Lisboa, e a circulação de pessoas por diferentes espaços do planeta, fatores que muito provavelmente contribuíram para a intensificação do desejo de conhecer mais sobre os rumores de outras partes. Mesmo que a notícia fosse um elemento fundamental na estruturação de novos sistemas de governança, o que se observa nos relatos que circulavam, de prensa ou de mão, é certo que não se tratavam de segredos de Estado, pelo contrário, eram mesmo inflamadas por um certo teor de curiosidade e encenação, almejadas tanto pelos que as reuniam em suas miscelâneas, quanto pelos que as liam ou ouviam em voz alta. Caberia, portanto, em decorrência desta constatação, a investigação acerca do comportamento do público leitor/ouvinte e consumidor das Relações de Sucessos e de Avisos, bem como dos canais de emissão e recepção que buscam se informar por meio dessa circulação pouco sistematizada e quase desconhecida fora do campo dos especialistas, num tempo em que não existia o que hoje denominamos de opinião pública (Megiani, 2012).

Com o incremento da tecnologia tipográfica as relações impressas apresentam características formais mais estáveis e comuns do que as manuscritas, entretanto temos encontrado inúmeras relações copiadas de impressas quando estas se esgotavam ou eram de difícil localização. As impressas geralmente possuem portada, com imagens em xilogravuras relacionadas ao tema tratado e anúncio do título. É comum encontrarmos gravuras reaproveitadas, quando o tema se mantém semelhante. Temas de naufrágios e aparições da virgem, por exemplo, eram recorrentes nessas relações, podendo ser aproveitadas imagens de rosto 
que não prejudicariam o conteúdo. Na parte inferior da folha de rosto encontramos comumente os dados tipográficos e as licenças de impressão, no caso dos lugares onde havia censura régia e/ou inquisitorial. Entretanto, em função de condições adversas no momento da impressão, essas informações também ocorrem na última folha, após o final do texto, bem como a dedicatória. Essa variação pode ser determinada por razões técnicas ou mesmo em função do fluxo dessas informações, ou seja, o texto já estava pronto para sair da tipografia quando chega a licença, que vai parar no verso da última folha. A primeira inicial do texto geralmente era capital ou gravada, dependendo do nível e condições financeiras do impressor em possuir letras de diferentes tamanhos e formas (Pena Sueiro, 2001). O texto propriamente dito podia ser redigido em verso, mas principalmente em prosa, com as seguintes características: texto compacto, letra miúda economizando espaço, e se for em verso, estes eram editados em colunas separadas por ornamentos tipográficos - marcas de edição.

As relações se difundem nos ambientes letrados onde eram lidas e colecionadas por cortesãos, eclesiásticos e mercadores. Nos casos e coleções na península ibérica encontramos as relações mais difundidas nos meios cortesãos e eclesiásticos desde finais do século XV e que compunham muitos conjuntos de miscelâneas reunidas em diversos lugares (Megiani, 2009). Nosso interesse por esse tipo de fonte noticiosa surgiu durante a pesquisa para a tese de doutoramento sobre as visitas dos Filipes a Lisboa (1581 e 1619), fato noticiado e difundido por meio de Relações de Sucessos e Avisos, de diversos tamanhos e formatos (Megiani, 2004), com maior destaque para a jornada e entrada de Filipe III em 1619, que contou com muitos impressos e alguns folhetos avulsos descritivos acerca das arquiteturas efêmeras e arcos de triunfo elaborados para a ornamentação de Lisboa na ocasião. A visita de 1619 ficaria perpetuadas na obra de João Baptista Lavanha, publicada por Tomas Junti, ${ }^{5}$ que conta com gravuras impressas em Antuérpia. Embora tenha

5 LAVANHA, João Baptista, Viagem da catholica Real Magestad Del Rey Filipe II N.S, Impresso por Thomas Junti, Madrid, 1622 
sido designado cronista oficial da jornada, Lavanha não acompanhou o rei, tendo sido encarregado de compor a Viagem com base em relatos, relações e esboços de terceiros. Os impressores de Sevilha também se dedicaram especialmente a esse evento uma parte significativa de suas prensas, tais como Juan Serrano e Francisco de Lyra (Espejo, 2008).

A partir daquele estudo, começamos a pesquisar ritmos e fluxos de circulação da informação, na passagem do séc. XVI para o XVII, entre o centro das monarquias ibérica e seus domínios coloniais, tendo como fontes os conjuntos de coleções de notícias reunidos por indivíduos que tinham acesso a essas informações. Nesse sentido, observamos, ao lado de outros especialistas, que as populações europeias viveram uma espécie de "febre" pela busca de informação na primeira metade do século XVII, o que teria incentivado o aumento da demanda por esse gênero de relatos baratos e acessíveis também aos não alfabetizados, já que eram lidos em voz alta. Isso explica porque a Guerra dos Trinta Anos (1618-1648), por exemplo, foi o momento em que as relações mais se difundiram, demonstrando o grande interesse em conhecer episódios do conflito. Ou então o uso das notícias feito pela Coroa portuguesa durante a chamada Guerra de Restauração entre 1640 e1668 (Mendes, 2018), ou ainda as guerras contra os holandeses no Brasil que, como dissemos, suscitaram também uma intensa procura por relatos, em língua portuguesa, espanhola, holandês, italiana, inglesa e francesa. Desse modo, as notícias sobre a invasão e expulsão dos holandeses da Bahia entre 1624 e 1625 (Cameniestzki; 2005), a invasão de Pernambuco pela Companhia Holandesa das Indias Ocidentais (West-Indische Compagnie - WIC) em 1635 e a Restauração portuguesa de 1640 tornaram-se temas frequentes nas relações de sucessos impressas e manuscritas, podendo ser encontradas em qualquer acervo relativo ao período. ${ }^{6}$

6 Um dos textos dedicados à Aclamação de D. João IV no Brasil foi Relaçam da aclamação que se fez na Capitania do Rio de Janeiro do Estádo do Brasil, \& nas mais do Sul, ao Senhor Rey Dom João o IV. por verdadeiro Rey, \& Senhor do seu Reyno de Portugal, com a felicissima restituiçaõ, q[ue] delle se fez a sua Magestade que Deos guarde, \&c. Lisboa: por Iorge Rodrigues: a custa de Domingos Alures livreiro, 1641. 
O crescente interesse observado em relação aos textos noticiosos de guerras e batalhas a partir de inícios do século XVII (Bebiano, 2000), ocorre também com os textos religiosos, que correspondem à maioria dos volumes localizados em pequenas coleções de livros de particulares. Orações, trechos e episódios de vidas de santos, sermões e novenas, são alguns dos exemplos identificados. Além desses, também gravuras com imagens de santos e passagens bíblicas. Da mesma forma, calendários religiosos eram impressos e distribuídos para serem afixados, copiados e memorizados. Assim como os panfletos de novidades, os impressos religiosos adotavam os formatos usados pelas congregações para a divulgação de seus padroeiros e protetores. Sabemos, por exemplo, que esses impressos, e manuscritos adquirem também o caráter mágico de proteção - que guardam até hoje - à medida que seu conteúdo se transfigura e adquire poder de cura, de bênção, de redenção. Nossas notícias não têm esse caráter, embora contivessem outras funções imateriais. Por exemplo, as relações sobre milagres e acontecimentos religiosas podiam adquirir os atributos do seu próprio conteúdo, mesmo que não tivessem sido impressas para esse fim. O relato de uma aparição da virgem, se guardado em lugar seguro, junto do fiel, poderia adquirir uma função de proteção. Do mesmo modo, notícias contendo relatos de milagres de santos ou de batalhas vitoriosas de exércitos cristãos contra o de infiéis ou hereges podiam ter poder de redenção e salvação.

Outra modalidade de impressos avulsos e soltos muito comuns eram aqueles textos que podiam ser representados, tais como peças de teatro, pantomimas e autos religiosos, espécie de mescla intermediária entre escrita, oralidade e visualidade, tão característica da cultura em que a letra era ainda a forma menos usual de comunicação e expressão (Curto, 2007). Mesmo as modalidades mais elevadas, praticadas por letrados eruditos e vinculados às instituições de saber, universidades, academias e à própria monarquia, encontravam-se atreladas a padrões retóricos formais, oriundos de práticas orais tradicionais, incorporadas ao texto. Os estudos filológicos, linguísticos e etimológico das formas escritas, na passagem da época medieval para a moderna, ajudam a explicar como sobreviveram tais fórmulas orais (cf. Castillo Gómez, 1999), a ponto de 
organizarem o próprio relato escrito. Nesse sentido, reforçamos a ideia de que textos avulsos não podem ser entendidos fora de seus contextos de circulação, ambientes, usos e práticas de leitura (Zumthor, 1987).

No contexto, outra difundida prática da circulação de textos avulsos, sobretudo na Espanha do século XVII, era a de aconselhamento para resolução de problemas da vida material do reino, da Coroa e das conquistas, conhecida como Arbítrios. Embora possua características textuais e significados específicos, também passa a integrar esses conjuntos de relações, presentes invariavelmente nesses códices chamados de miscelâneas. Estamos, portanto, diante de um momento de intensificação e difusão dos modos particulares de coletar, organizar e preservar a informação escrita, associado aos processos de formação da burocracia das monarquias modernas, marcados pela sofisticação das formas de conhecimento e novas configurações sociais nos ambientes de corte, que colocam aos letrados possibilidades de mobilidade através do fortalecimento de vínculos permeados pela escrita.

No que tange à dinâmica de remessa de notícias e relatos, impressos ou manuscritos, e seu papel na consolidação de um conhecimento/ memória sobre o mundo novo, A.J.R. Russell-Wood destacou a importância do registro e da circulação de informações entre as partes do Império português durante os séculos XV, XVI e XVII para a construção de um conhecimento novo e de uma memória desse conhecimento, produzidos a partir do uso de relatos orais de pessoas que regressaram de temporadas no além-mar. Para ele,

(...) a qualidade, a riqueza e a diversidade das informações reunidas estão patentes em crônicas, narrativas de viagens, relatórios de embaixadores, carta de jesuítas, diários e correspondência oficial”. (...) Parece não ter havido faceta da experiência humana que tenha escapado aos olhos de lince e aos excelentes ouvidos dos portugueses, nas suas peregrinações. (...) Tais informações forneceram os materiais usados por cronistas oficiais e por historiadores os quais, não só tinham acesso, sem restrições, a todos os relatórios que entravam em Portugal, mas podiam recorrer a testemunho oral riquíssimo daqueles que regressavam de 
além-mar. Igualmente, conselheiros reais, estrategas militares, prospectores comerciais e até membros do clero recorreram a essas mesmas fontes para tomar decisões no interesse da Coroa, do País e da Cristandade (Russel Wood, 1998, p.97).

Em relação à localização das principais oficinas tipográficas da Europa, de onde saiam a maior parte dos objetos impressos Ana Buescu, seguindo na esteira de Lucien Febvre, afirma que

Uma análise dos mapas relativos à implantação da arte tipográfica permite concluir que não existe uma coincidência com o quadro da repartição das universidades, ultrapassando-o largamente e, por outro lado, constatar a forte presença dos impressores e dos ofícios e actividades ligados à produção e ao mercado do livro nas grandes rotas do comércio europeu, terrestres ou marítimas - é o caso de Augsburgo, Frankfurt, Rouen, Nantes, Antuérpia ou Lyon, cidade em que em 1500 possui mais de cinquenta livreiros-editores (Buescu, 2000, p.34).

Desse modo, entendemos que, durante a Alta Idade Moderna, a opção das tipografias pelo posicionamento em locais próximos de centros por onde passavam as rotas de comércio e circulação de mercadorias demonstra, por um lado, que impressos também se tornaram importantes objetos de comercialização, e participavam dos mesmos circuitos por onde circulavam mercadores, navegadores, portadores de meios de transporte. Esta, aliás, é uma questão que merece ser melhor entendida.

\section{JERÔNimo MASCARENHAS E SUA COLEÇÃo DE NOTÍCIAS}

Finalmente, passaremos a tratar de maneira mais concreta acerca do interesse pelas notícias, abordando a coleção de manuscritos e impressos avulsos construída pelo clérigo português Jerônimo Mascarenhas. ${ }^{7}$

7 Nosso interesse pela produção do bispo Jeronimo Mascarenhas ocorreu, inicialmente, durante uma investigação de pós-doutorado em Madrid no ano de 2006, sob a supervisão de 
Nascido em Lisboa no ano de 1611 e falecido em Segóvia em 1671, Jerônimo Mascarenhas pertenceu a uma família de considerável destaque durante o período filipino. Era o $6^{\circ}$ filho de D. Jorge de Mascarenhas, $1^{\circ}$ Marquês de Montalvão e $1^{\circ}$ Vice-Rei do Brasil, cujo título fora concedido por Felipe IV no ano de 1639. Sua mãe era D. Francisca de Vilhena, sobrinha de seu pai. Era primo de D. Fernando de Mascarenhas, o $1^{\circ}$ conde da Torre, e irmão de D. Francisco de Mascarenhas, $2^{\circ}$ conde de Castelnovo, além de outros irmãos também distinguidos por Felipe IV. Alguns membros da família Mascarenhas engajaram-se em movimentos sediciosos de Évora contra a pressão de Olivares em 1639, e receberam punições exemplares por parte da coroa nos momentos que antecederam a aclamação de D. João IV. Em contrapartida, após a aclamação brigantina, integrantes da família também foram tratados como traidores pela Coroa portuguesa - o caso do próprio pai de Jerônimo, D. Jorge de Mascarenhas, encarregado de promover a aclamação do novo monarca no Brasil embora fosse Vice-Rei dos Habsburgos (cf. Valladares, 2006).

Jerônimo, entretanto, não aparece nesses contextos de rebelião e traição nos quais estiveram envolvidos seus irmãos, primos e o próprio pai, e o estudo de sua trajetória nos permite investigar um comportamento do cortesão em busca de aceitação social por meio da escrita. Formado e doutorado em Cânones em Coimbra, Jerônimo Mascarenhas teve pouco destaque depois de sua titulação em 1631, período sobre o qual pouco se sabe sobre sua atuação. Mesmo tendo vivido a maior parte de sua vida juvenil em território português, transfere-se para Madrid após a aclamação de D. João IV, ingressando na corte de Felipe IV, onde também se encontrava seu irmão mais jovem, o Conde D. Pedro Mascarenhas, $2^{\circ}$ Marquês de Montalvão. Ambos estiveram do lado oposto dos demais familiares durante a Guerra de Independência de Portugal. De Felipe IV

Fernando Bouza, com apoio da FAPESP. Contudo, devido ao volume de material da Coleção Mascarenhas, temos desenvolvido a pesquisa aos poucos, em estadas mais curtas realizadas em 2015 e 2018, Atualmente, o estudo está sendo financiado pelo projeto Circulación de personas, libros, objectos y noticias entre Brasil y los territorios de la Monarquía Hispánica (1580-1668), financiado pelo Ministério da Economia da Espanha e coordenado pelo Prof. Dr. Jose Manuel Santos Perez, da Universidade de Salamanca, período 2017-2020. 
Jerônimo Mascarenhas recebe, entre outras, a nomeação como prior de Guimarães e bispo de Leiria, sem nunca ter exercido no local nenhuma dessas funções.

Segundo Rafael Valladares, Mascarenhas encontra-se já situado na corte de Felipe IV em fevereiro de 1641, quando recebe um título da Ordem de Calatrava, sobre a qual escreveria uma obra de História em tom apologético. Em outubro de 1642, foi proclamado castelhano no Conselho Régio, e em 1647 passa a Capelão-mór e Limosnero-mór da Casa da Rainha D. Mariana de Áustria, segunda esposa de Felipe IV, de quem também passa a ser confessor e cronista oficial. No ano de 1658, Mascarenhas passa a ocupar o cargo de Summiler de Cortina da Casa Real e ingressa no Conselho de Portugal, além de ser nomeado também para o cargo de Censor Régio, a partir do qual acompanha a produção escrita impressa na Monarquia Hispânica (Valladares, 2017). Em 1667, alcança o último posto de sua carreira eclesiástica como Bispo de Segóvia, onde morre em 1672.

A trajetória ascendente de Mascarenhas no coração da corte de Felipe IV, entretanto, não foi um caso excepcional entre os portugueses que serviram à Coroa entre 1580 e 1640, e mesmo depois desse período. Embora tenha sido bastante comum o posicionamento de uma historiografia portuguesa, de viés eminentemente nacional, dedicada ao estudo de escritos autonomistas durante a União das Coroas (Cidade, 1941), estudos mais recentes têm sido dedicados ao fluxo e à vinculação de integrantes das famílias de elite portuguesas na direção do centro do poder após a incorporação da Coroa de Portugal pela Monarquia Hispânica. Fernando Bouza, em trabalho pioneiro sobre o assunto, já demonstrava como em torno da paróquia de Santo Antônio dos Portugueses em Madrid criou-se um círculo de influências e uma rede de apoios recíprocos, que se fortaleceu a partir da ascensão do Duque de Lerma no reinado de Felipe III (Bouza, 2000). Ao lado da nobreza tradicional e de uma nova nobreza recém titulada, também cristãos novos portugueses encontram espaço entre os favores da Monarquia Hispânica. Segundo Ana Hutz, "a aproximação dos cristãos novos com a Coroa culminaria na solicitação de um perdão geral no final do século 
XVI, cuja negociação se prolongou por quase uma década" (Hutz, 2017, p.116). Com a ascensão do Conde Duque Olivares o grupo português se fortalece ainda mais, sobretudo após a aproximação de Diogo Soares e Miguel de Vasconcelos ao valido, e o número de famílias que se transferem para Madrid se amplia, pelo menos até 1638 (Schaub, 2001). Também Rafael Valladares dedicou um artigo de seu livro Por toda la tierra a portugueses que permaneceram em Madrid após 1640 (Valladares, 2017). Temos ainda o estudo de Mathias Glöel que analisa os autores portugueses que escreveram no contexto da Monarquia Hispânica, demonstrando que a escrita sobre e no reino de Portugal sofreu câmbios de abordagem a partir de 1580, mesmo quando continuava a exaltar o reino luso (Glöel, 2016). Por outro lado, autores que dedicaram suas obras a Felipe IV, por exemplo, tornam-se enfáticos defensores da Restauração e de D. João IV após 1640, o que levanta uma série de outros problemas que não teremos condições de tratar aqui (cf. Torgal, 1981).

Além das obras impressa e manuscritas de sua autoria, Mascarenhas construiu uma vasta coleção de notícias que nos legou de maneira praticamente intacta. Os quarenta e oito tomos que compõem hoje a Coleção Mascarenhas da Biblioteca Nacional de Espanha, objeto de nossa pesquisa em desenvolvimento, têm como ponto de partida o ano de 1598 - o mesmo da morte de Felipe II de Espanha - e terminam no ano de 1666 - quando da morte de Felipe IV, catalogados entre os manuscritos 2346 e 2393 da BNE. Não localizamos, até o momento, estudos específicos sobre esses volumes e sua forma de organização, e nosso interesse por eles deve-se, sobretudo, à maneira como o cronista coletava as informações e organizava os registros. Além dos volumes organizados pelo próprio Mascarenhas, existem três códices anteriores, os quais teriam inspirado a continuidade do colecionador de notícias. Esses volumes são atribuídos ao jesuíta Jerónimo Roman de La Higuera (1538-1611), que teria escrito, entre outras obras, os Sucessos desde o ano $1^{\circ}$ DC até o ano 719, catalogados como Códices 2343, 2344 e 2345 da BNE. No registro do Catálogo, esses códices pertencem à Coleção Mascarenhas, o que significa que chegaram à BNE junto com os demais 48 tomos. No Inventário de Manuscritos de la BNE, aparece a 
seguinte observação nesses 3 tomos: "Este manuscrito pertenece, como el anterior, a una Colección que mandó hacer D. Jerónimo Mascareñas, obispo de Seggovia, de copias y extractos de las obras del P. Román de la Higuera, especialmente de su Historia eclesiástica de la imperial ciudad de Toledo".

Os tomos organizados por Mascarenhas estão repletos de cartas e relatos - originais e cópias - enviadas de todas as cortes mais importantes da Europa, partes do Oriente e Ocidente, especialmente norte da África, além de inúmeras compilações de documentos antigos, especialmente relativos às relações entre as monarquias de Espanha e Portugal. A grande maioria dos textos está traduzida para o castelhano, o que demonstra a relação visceral de Mascarenhas com essa língua adotada por ele como natural. Seus textos autorais, que abrem cada volume como uma crônica daquele ano, foram também escritos em língua castelhana, indício de vínculo também da maior parte de portugueses que se transferiram de Portugal para a corte no mesmo período.

Com relação à estrutura geral do conjunto, nem todos os tomos correspondem a um ano, alguns deles reúnem vários anos, sobretudo os primeiros: 1598 a 1600, 1601 a 1610, 1611 a 1617. Além desses mais múltiplos, também há os tomos que reúnem dois anos em um volume: $1631 / 1632,1645 / 46,1655 / 56,1659 / 60$. O ano de 1625 é o único que se divide em dois tomos, e o de 1641 está separado em um sobre Sucesos del año 1641 e outro denominado Rebelión de Portugal año 1641. Também identificamos que há uma considerável quantidade de documentos de anos que não correspondem à data do volume, ou seja, o ano indicado no título do tomo não tem exclusivamente documentos daquele ano, o que derruba qualquer tentativa de generalizar a sua análise. Será, portanto, necessário registrar cada documento referente ao ano de datação e ao ano do tomo no qual está encadernado.

Jerônimo Mascarenhas conseguiu reunir um volume muito grande de informações e uma rede vasta de correspondentes, cujos nomes nem sempre aparecem referidos. Há um grande número de cópias de documentos oficiais entre as notícias, o que demostra que ele teria acesso a pessoas que atuavam no centro de cortes como a francesa, a inglesa e 
a papal, entre outras. Além disso, a coleção começa em 1598, mas seu nascimento data de 1611, o que significa que teria tido acesso a fontes anteriores à sua existência por meio de herança de alguém que possuía esse material, entretanto não localizamos ainda informações sobre como teria obtido tais fontes. Tais imprecisões são características da escrita do período, já que o uso de referências a fontes documentais não era obrigatoriamente um critério de autoria. É provável que tenha tido acesso aos registros e informações existentes no Conselho de Portugal, onde passou a ter assento a partir de 1641. Também seu cargo de Censor Régio, para o qual fora nomeado por Felipe IV, facultou a ele uma rede ampla de autores e de notícias sobre obras impressas e manuscritas que circularam nos territórios da Monarquia Hispânica, sobretudo folhetos avulsos, Relaciones de Sucesos, Avisos, e outros tipos de escritos breves que compõem uma parte significativa de seus papéis.

Cada tomo da coleção possui índice escrito com letra e tinta do século XVIII, bem como a encadernação posterior à época em que viveu Mascarenhas. Isso se deve ao fato de terem pertencido a outro colecionador de documentos antigos antes de chegarem à Biblioteca Real e Biblioteca Nacional, o IV Duque de Uceda D. Juan Francisco Pacheco Telles de Guzmán, Vice Rey da Sicilia (1687-1692). Segundo os importantes estudos de Martín Velasco, a biblioteca do IV Duque de Uceda possui encadernação própria que permite identificar todo o conjunto de impressos e manuscritos pertencentes a esse nobre no acervo da Biblioteca Nacional de Espanha (Martin Velasco, 2009; Fernández Pomar, 1976). Não há informações, até o momento, sobre como os volumes construídos por Jerônimo Mascarenhas teriam chegado à biblioteca do Duque de Uceda. Acreditamos, contudo, que eles tenham sido comprados, já que durante sua permanência como Vice-Rei da Sicilia, D. Juan Francisco Pacheco Telles de Gusmán tornou-se um notório comprador de manuscritos antigos, gregos, latinos e árabes, que também se encontram encadernados e depositados na Biblioteca Nacional de Espanha e despertam grande interesse dos historiadores das coleções do século XVII.

$\mathrm{O}$ estudo, em andamento, dos volumes organizados por Mascarenhas tem nos mostrado que a preocupação com o controle das notícias e 
informações no centro da corte da Monarquia Hispânica se aprimorava e buscava desenvolver uma sistemática baseada na cronologia, muito mais do que nos assuntos. A organização dos volumes da coleção por anos - mesmo que não seja extremamente rigorosa - se manifesta em paralelo ao surgimento dos primeiros periódicos noticiosos. A preocupação em sistematizar a informação de maneira temporal se tornaria, em pouco tempo, um padrão generalizado. Desde os inícios do século XVII, podemos identificar o aparecimento das primeiras Gazettas e dos primeiros Mercúrios, que apresentavam regularidade mais constante, embora ainda pouca estabilidade em termos de autoria, estilo ou mesmo preço. Destinavam-se a circular e informar o maior número de pessoas possível ao mesmo tempo. O crescimento desses formatos ao longo do seiscentos, e sobretudo no século XVIII, acabou ocorrendo também na modalidade manuscrita, já que encontramos em Portugal uma incidência de gazetas que não passaram pela impressão, mas que recebiam tratamento muito semelhante e cuja autoria costuma ser atribuída a um autor que faz o papel de editor (Duarte, 2012). À medida que o mercado notícias vai se tornando mais valorizado e rentável, surgem impressores mais especializados e autores que cobram pela informação. Esses processos integrados proporcionam o surgimento de práticas coletivas e individuais que deram origem a novos mecanismos de seleção e organização da memória, como foi o do nascimento das Gazetas de Notícias. ${ }^{8}$ Contudo, os papéis avulsos não serão substituídos pelos periódicos regulares, já que a escrita e publicação de Avisos e Relações de Sucessos continua a existir, embora em menor proporção. Seu desaparecimento será lento e muito desigual em cada região da Europa e América.

À guisa de reflexão final ainda gostaríamos de acrescentar que o desenvolvimento das pesquisas acerca da cultura escrita nos reinos ibéricos e seus domínios coloniais tem demonstrado a necessidade de

8 LISBOA, João Luís; MIRANDA, Tiago C.P. dos Reis, OLIVAL, Fernanda (eds.) Gazetas Manuscritas da Biblioteca Pública de Évora. Vol. 1 (1729-1731). Lisboa: Colibri, 2002. LISBOA, João Luís, MIRANDA, Tiago C.P. dos Reis, OLIVAL, Fernanda (eds.) Gazetas Manuscritas da Biblioteca Pública de Évora. Vol. 2 (1732-1734). Lisboa: Colibri, 2005. 
ultrapassar as análises que se baseiam na tríade escrita-leitura-memória, já que se trata de um vasto mundo conectado por meio de papéis escritos, raramente fixados na forma impressa no caso de Portugal e seus domínios, excetuando-se sempre o caso dos jesuítas detentores de uma tecnologia comunicativa altamente sofisticada em função de sua "missão universal civilizadora". No caso do Brasil, durante muito tempo considerou-se que, além da exploração agrícola e da escravidão, uma outra característica emblemática da colonização portuguesa na América fora a ausência de duas instituições fundamentais da cultura europeia: a primeira medieval - a universidade - e a segunda renascentista - a imprensa (Holanda, 1991). Na América Espanhola, contudo, essas instituições estiveram presentes desde a primeira metade do século XVI. À inexistência dessas instituições na América portuguesa acabou-se por vincular, em grande medida, o suposto "atraso" na formação e crescimento de uma camada letrada e independente, aqui formados e instruídos, gerando uma sociedade carente de bases fundamentais da cultura "erudita", e desprovida de condições para pensar uma nação para além do binômio agrarismo/escravidão (Villalta, 1997). Vale lembrar, entretanto, que embora não tendo sido criada na América, ao menos em outras partes do Império português existiu imprensa também desde a primeira metade do século XVI, marcando a ação dos evangelizadores da Cia. de Jesus no Oriente (Matos, 1997). Em Goa, a tipografia foi criada em 1556; em Macau, no ano de 1588; e no Japão as primeiras oficinas surgem em 1590 (Boxer, 1975; 1981). Paralelamente ao desenvolvimento da imprensa no reino e nas conquistas, vemos aprimorarem-se os mecanismos de censura inquisitorial e controle da circulação e comercialização de livros e impressos dos mais diversos tipos (Megiani, 2006).

Além disso, se por um lado a ausência de tipografias e universidades tornou-se uma espécie de estigma do "atraso", por outro é necessário ressaltar a importância dada ao ensino da língua portuguesa como forma de controle e vinculação nas relações Portugal-Brasil desde o início do século XVI. Atrelada à presença das ordens religiosas detentoras do monopólio do ensino da leitura nos trópicos lusitanos, a ausência de tais 
instituições de caráter laico para difusão da cultura letrada europeia foi determinante para a conformação das ideias no Brasil durante o período colonial. Por outro lado, é bastante conhecida a circulação clandestina de livros impressos como fator significativo da formação de núcleos de resistência de colonos letrados contra o acirramento de medidas metropolitanas durante a segunda metade do século XVIII. Contudo, até muito recentemente, a historiografia não considerou que ao longo de mais de três séculos de colonização a cultura escrita esteve presente na forma manuscrita - de modo oficial, ou não, - como base da estrutura comunicativa construída entre Portugal e suas conquistas, bem como nas várias partes do império português. Trata-se de uma constatação simples, de certa maneira óbvia, mas pouco discutida diante do significado que ela possui, já que os estudos mais recentes têm demonstrado que diversas foram as formas de difusão da cultura escrita nos tempos da colonização portuguesa, predominando indiscutivelmente o modo manuscrito (cf. Hermann; Azevedo; Catroga, 2012). O estudo da circulação de notícias por meio de folhas avulsas, Relações de Sucessos e Avisos está ainda em seus primórdios, e o volume de fontes anuncia que ainda há muito caminho por percorrer.

O estudo de coleções de livros, da circulação de ideias, notícias, relatos e memórias; dos usos da escrita no campo administrativo, no campo místico-religioso e evangelizador, abre importantes vertentes para se buscar a compreensão dos mecanismos de encontro da cultura europeia com as culturas que passaram a se conectar a ela após a criação dos Impérios ultramarinos. $\mathrm{O}$ aprofundamento da análise do sistema de comunicação escrita entre as várias partes do globo durante a Alta Idade Moderna permitirá refletir sobre a permanência e a continuidade de práticas culturais desenvolvidas nas metrópoles que, de certa forma, além de se estenderem aos domínios ultramarinos, articularam e uniram as diversas partes dos impérios ibéricos, construindo as bases sobre as quais se efetivaram as relações de colonização. Através da integração dos elementos oral/textual/visual, um conjunto de códigos de comunicações expressa e transmite valores simbólicos e significados de vários tipos: econômicos, sociais, políticos, religiosos, étnicos, etc. O estudo 
dos sistemas de memória e comunicação é, portanto, um meio para se chegar à compreensão de auto representações, de identidades e de trocas culturais estabelecidas. O estudo da curiosidade de saber o que se passa fora de casa, a intenção em organizar ano a ano as informações, $\mathrm{o}$ fluxo de notícias e de rumores nos tempos da Alta Idade Moderna nos permitem vislumbrar ainda, as conexões entre diferentes concepções de temporalidade que se tornam cada vez mais padronizadas e comuns a todas as partes do planeta.

\section{REFERÊNCIAS BIBLIOGRÁFICAS}

BEBIANO, Rui. A Pena de Marte. Escrita da guerra em Portugal e na Europa (sécs. XVI-XVIII). Coimbra: Minerva, 2000

BOUZA, Fernando. Usos cortesanos de la escritura. Sobre lo escrito em los espacios áulicos del Siglo de Oro. Cultura \& Sociedad. Dossier: El escrito en la corte de los Austrias. n. 3, p.9-14, 2006.

BOUZA, Fernando. Portugal no tempo dos Filipes. Política cultura e representações (1580-1668). Trad. Lisboa: Edições Cosmos, 2000.

BOXER, Charles Ralph. O Império Colonial Português (1415-1825). Lisboa: Edições 70, 1981.

BOXER, Charles Ralph. A Tentative Check-list of Indo-Portuguese Imprints. Arquivos do Centro Cultural Português, vol. IX. Paris: Fundação Calouste Gulbenkian, 1975.

BRAUDEL, Fernand. El Mediterrâneo y el Mundo Mediterráneo en la Época de Felipe II. Tomo I. México: Fondo de Cultura Econômica, 1997.

BUESCU, Ana Isabel. Memória e Poder. Ensaio de História Cultural (séculos XV-XVIII). Lisboa: Cosmos, 2000.

CAMENIESTZKI, Carlos Ziller; PASTORE, Gianriccardo Grassia. 1625, o Togo e a Tinta: a batalha de Salvador nos relatos de guerra. Topoi, vol. 6, n. 11, jul-dez, p.261-288, 2005.

CASTILLO GÓMEZ, António. (org.). Escribir y leer en el siglo de Cervantes. Barcelona: Gedisa, 1999.

CHARTIER, Roger. (coord.). As utilizações do objecto impresso. Lisboa: DIFEL, 1998. 
CHARTIER, Roger. Leitura e leitores na França do Antigo Regime. São Paulo: UNESP, 2004.

CIDADE, Hernani. A literatura autonomista sob os Filipes. Lisboa: Livraria Sá da Costa, 1941.

CROUZET, Denis. Nostradamus: une medicine des âmes à la Renasissence. Paris: Payot, 2011.

CURTO, Diogo Ramada. Cultura Escrita. Sécs XV a XVIII. Lisboa: Instituto de Ciências Sociais, 2007.

DARNTON, Robert. O Beijo de Lamourette. Mídia, Cultura e Revolução. São Paulo: Cia. das Letras, 1990.

DUARTE, Ligia Gaspar. O correr da pena nas Gazetas Manuscritas (1735-1738). Lisboa: FCT, 2012.

ESPEJO, Carmen. El mercado de noticias en Sevilla: de las relaciones a las gacetas. Relaciones de Sucesos en la BUS. Antes de que existiera la prensa. 2008. Disponível em http://expobus.us.es/relaciones/ ARTICULOS/articulo3.pdf. Acesso em 15 ago. 2018.

FERNÁNDEZ POMAR, José Maria. La colección de Uceda de la Biblioteca Nacional. Nueva edición del catálogo de manuscritos. Helmántica, tomo 27, n. 84, p.475-518, 1976.

GLÖEL, Matthias. Los autores portugueses entre 1580 y 1640: una lucha literaria por la preeminencia en la monarquía hispânica. Revista de Historia, vol. 1, n. 23, ene-jun, p.29-51, 2016.

HERMANN, Jacqueline; AZEVEDO, Francisca Lucia Nogueira; CATROGA, Fernando. (orgs.). Memória, escrita da história e cultura política no mundo luso-brasileiro. Rio de Janeiro: Ed. FGV, 2012.

HOLANDA, Sérgio Buarque. O semeador e o ladrilhador In: HOLANDA, Sérgio Buarque. Raízes do Brasil. Rio de Janeiro: Jose Olympio, 23a ed. 1991. HUTZ, Ana. Homens de nação e de negócios. Redes comerciais no mundo ibérico (1580-1640). São Paulo: Intermeios, 2017.

KOSELLECK, Reinhart. Futuro Passado. Contribuição à semântica dos tempos históricos. Rio de Janeiro: Contraponto, 2006.

MAGALHÃES, Pablo Iglesias. A Jornada dos Vassalos por D. Jerônimo de Ataíde em 1625. Revista do IHGB. Rio de Janeiro, vol. 471, p.219-280, abr-jun. 2016 
MARTIN VELASCO, Margarita. La biblioteca del IV Duque de Uceda. Una colección europea. Teka Kom. Hist. OL PAN, p.219-232, 2009.

MATOS, Manuel Cadafaz de. A tipografia quinhentista de expressão cultural portuguesa no Ocidente (Índia, China e Japão). Tese (Doutorado em História) - Universidade Nova de Lisboa. Lisboa, 1997.

MEGIANI, Ana Paula Torres. O rei ausente. Festa e cultura política nas visitas dos Filipe a Portugal (1581-1619). São Paulo: FAPESP/Alameda, 2004.

MEGIANI, Ana Paula Torres. Imprimir, regular, negociar: elementos para o estudo da relação entre Coroa, Santo Ofício e impressores no mundo português (1500-1640). Anais de História do Além-Mar VII. CHAM Universidade Nova de Lisboa, 2006.

MEGIANI, Ana Paula Torres. Memória e conhecimento do mundo: coleções de objetos, impressos e manuscritos nas livrarias de Portugal e Espanha, séculos XV-XVII. Anais do Museu Paulista, vol. 17, n .1, p.155-171, 2009.

MEGIANI, Ana Paula Torres. Contar coisas de todas as partes do mundo. As Relaciones de Sucesos e a circulação de notícias escritas no período filipino. In: ALMEIDA, Suely Creusa Cordeiro de; SILVA, Gian Carlo; RIBEIRO, Marília de Azamburja (Orgs.). Cultura e Sociabilidades no Mundo Atlântico. Recife: Editora Universitária UFPE, 2012. p.469-483. MENDES, Caroline Garcia. Gazetas, Mercúrios e Relações de Sucessos. A produção e a circulação de notícias impressas na Península Ibérica. Segunda metade do século XVII. Tese (Doutorado em História) - Universidade de São Paulo. São Paulo, 2018.

MONTEIRO, Rodrigo Bentes; CALDEIRA, Ana Paula Sampaio. A ordem de um tempo: folhetos na coleção Barbosa machado. Topoi, vol. 8, n. 14, p.77-113, 2007.

PENA SUEIRO, Nieves. Estado de la cuestión sobre el estudio de las Relaciones de sucesos. Pliegos de bibliofilia, n. 13, p.43-66, 2001.

PIEPER, Renate. Cartas de nuevas y avisos manuscitos en la época de la imprenta. Su difusión de noticias sobre América durante el siglo XVI. In: BOUZA, Fernando. (coord.) Cultura epistolar en la alta Edad Moderna. Usos de la carta y de la correspondencia entre el manuscrito y el impreso. Cuadernos de Historia Moderna. Anejos IV. Madrid: Universidad Complutense de Madrid, 2005. p.83-94. 
REDONDO, Augustin, Entre Francia y España: el asesinato del rey galo Enrique IV (1610) y sus repercusiones a través de las relaciones de sucesos. In: GARCÍA LOPEZ, Jorge; BOADAS, Sònia (eds). Las relaciones de sucesos en los cambios políticos y sociales de la Europa Moderna. Barcelona: Editora Universidad Autónoma de Barcelona, 2015. p.109-123. RUEDA RAMÍREZ, Pedro. (dir). El libro en circulación en el mundo moderno en España y Latinoamérica. Madrid: Calambur Editorial 2012.

RUSSELL-WOOD, Anthony John R. Um mundo em movimento. Os portugueses na África, Ásia e América (1415-1808). Lisboa: DIFEL,1998.

SALES, Mariana. Os manuscritos de Jules Mazarin sobre a expulsão dos holandeses da Bahia (1625). Testemunhos de bibliofilia ou interesse geo-estratégico? Portal A França no Brasil. Biblioteca Nacional - Rio de Janeiro, BnF. Disponível em: https://bndigital.bn.gov.br/ dossies/dossie-antigo/logicas-coloniais/escritos-e-correspondencias/ os-manuscritos-de-jules-mazarin/?lang=fr Acesso em 09 mar. 2019.

SCHAUB, Jean-Frédéric. Le Portugal au temps du comte-duc d'Olivares (1621-1640): le conflit de juridictions comme exercice de la politique. Madrid: Casa de Velázquez, 2001.

SCHWARTZ, Stuart. Da América Portuguesa ao Brasil. Estudos Históricos. Lisboa: DIFEL, 2003.

TORGAL, Luis Reis. Ideologia política e teoria do estado na Restauração. 2 vols. Coimbra: Imprensa da Universidade de Coimbra, 1981.

VALLADARES, Rafael. Por toda la tierra. España y Portugal. Globalización y Ruptura (1580-1700). Lisboa: CHAM, 2017.

VALLADARES, Rafael. Las dos guerras de Pernambuco. La armada Del conde da Torrey la crisis del Portugal hispánico (1640-1669). In: SANTOS PEREZ, Jose Manuel dos. El desafío holandés al dominio ibérico en Brasil en el siglo XVII. Salamanca: Ediciones Universidad de Salamanca, 2006. p.34-66.

VILLALTA, Luiz Carlos. O que se fala e o que se lê: língua, instrução e leitura In: SOUZA, Laura de Mello (org.). História da Vida Privada no Brasil. Vol 1. São Paulo: Cia. das Letras, 1997.

ZUMTHOR, Paul. A letra e a voz. A "literatura" medieval. São Paulo: Cia. das Letras 1987. 